\title{
The Process-oriented Assessment Model of Business English Translation Course in a Flipped Learning Context
}

\author{
Lijun Deng ${ }^{1}$ \\ ${ }^{1}$ School of English for International Business, Guangdong University of Foreign Studies, Guangzhou, China \\ Correspondence: Lijun Deng, School of English for International Business, Guangdong University of Foreign \\ Studies, 2 Baiyun Ave (N), Baiyun District, GZ 510420, China. E-mail: rejoice0707@126.com
}

Received: July 30, 2020

Accepted: August 17, $2020 \quad$ Online Published: August 28, 2020

doi:10.5539/hes.v10n4p1

URL: https://doi.org/10.5539/hes.v10n4p1

\begin{abstract}
Based on the preliminary research findings in the project-based flipped learning model in Business English Translation course, this study designed a process-oriented assessment model for this course and tested its efficacy by an empirical study on 181 third-year English major students divided into three experimental class and three control class under a flipped learning context. The process-oriented assessment model in Business English Translation course is both synchronic and diachronic, by incorporating multiple assessment subjects including both the teacher and the students and the complete learning activities before, during and after class. This study conducted a pre-test and an after-test to examine the students' command of key translation knowledge and skills, and meanwhile, to evaluate the improvement of students' translation competence after the implementation of the process-oriented assessment mode. Questionnaires and surveys were also employed in this study so as to collected students' response to the new assessment model. The data and results collected from the above-mentioned research methods indicate that the process-oriented assessment model can significantly enhance students' motivation and performance in Business English Translation course.
\end{abstract}

Keywords: process-oriented assessment, flipped classroom, Business English Translation course

\section{Introduction}

In the past decades, China's education evaluation system has undergone the transfer from test culture to assessment culture. The process-oriented assessment emphasizes the students' learning process and includes multiple evaluation subjects and immeasurable factors into the evaluation system so as to judge the learning process, motivation and effect and products. With the purpose of sustainable development for learners, the process-oriented assessment highly promotes students' motivation in learning and reflection (Gao, 2004).

Translation is a process in which the translator constantly modifies and improves the translation quality step by step. The translation process is characterized by the subjectivity and initiatives of the translator in rendering the source text into target text. Daniel Gale (1994) has pointed out that since translation is a process that translators constantly revise, negate and finally improve the translated version, translation instructors should focus on translation process instead of merely on the product of translation. The process-oriented assessment model in business translation courses, emphasizing students' learning motivation, process and products, is in line with the above-mentioned nature of translation process and can provide the most direct evaluation method (Zhong, 2005). From the perspective of the psychological characteristics of translation activities, the process-oriented assessment not only provides insight into the psychological processing of translation language (speech acceptance and speech production), but also reflects the psychological strategies adopted by translators, therefore it can explain the emergence of translated text as a psychological process. What's more, from the perspective of evaluation method, the use of procedural analysis in the empirical study of translation performance describes the process of translation formation and psychological developments in the translator's mind (Chang, 2002).

In addition, the process-oriented assessment also conforms to the inherent requirements of the flipped classroom. Flipped classroom incorporates learners in the subject category of learning and emphasizes the openness of the learning process. Flipped classroom extends the knowledge-learning process to the outside of the classroom, and requires the students to acquire knowledge independently with the help of instructional videos made by the teachers. Therefore, the assessment model of flipped classroom should also possess the nature of process-oriented, multi-subjected and open-process. 
However, till date, the academia has yet more to dwell on how to apply the process-oriented assessment framework to the empirical research in specific classroom teaching, and more specifically, in a flipped classroom context. This modern teaching model has witnessed great development in China in the past five years, but the researches on the assessment model of flipped classroom are still very limited. 65\% of the Chinese flipped classroom still adopt the traditional summative assessment method (Deng, 2018). Consequently, it is of crucial significance to develop a well-designed process-oriented assessment model in a flipped learning context.

\section{Literature Review}

\subsection{The Research on Process-oriented Assessment in China}

With the development of modern educational evaluation culture in China, process-oriented assessment has become an inevitable trend of Chinese curriculum and evaluation reform and development. Statistics from CNKI (China National Knowledge Infrastructure, an all-inclusive database for all Chinese academic journals, publications, conference articles and post-graduate dissertations) demonstrate a sharp increase of research papers with "process-oriented assessment" as keywords. The increase is around 100 articles per year from 2003 to 2019. The research team synchronically divided these papers and publications into two categories. The first category are mainly studies focusing on the theoretical exploration of process-oriented assessment. Chinese scholars including Gao Linbiao (2004), Ji Yanhong (2013), Wu Weining (2006), Zhang Shuguang (2012), Zheng Mingda (2010), Zhong Mei (2004) and etc have made great contributions and progress in this category. They explored the philosophical roots, application scope, methods, organization strategies and values of process-oriented assessment models. The second category are empirical studies on the application of process-oriented assessment mechanism in primary and secondary school classrooms and science and engineering courses in college. There are relatively few empirical studies on English major courses. The existing few studies mainly focus on the teaching of College English and Comprehensive English. Naturally, the studies on process-oriented assessment research in translation courses are even rarer. Chen Jirong (2013) contributed theoretical reflections on the process-oriented teaching in translation classroom, Liu Xiling (2014) studied the formative assessment model in translation teaching and concluded that formative assessment should be widely applied in translation courses. Zhang Xiumei (2014) and Wen Tong (2016) reflected on classroom teaching and assessment in English-Chinese translation courses and drew similar conclusions that assessment methods should be in line with the reform of teaching methodology.

On the other hand, the research on flipped learning has gained dramatic growth and popularity around the world since 2000. In China, the statistics from CNKI show that the number of research publications with "flipped learning" and "flipped classroom" as key words soared from 5 in 2012 to 19,059 in July 2020. The Chinese academia have also greatly enriched their understanding of the flipped learning pedagogy in English translation courses. However, there is much to be desired concerning the depth, framework, model, rationale and assessment model of flipped learning in English translation teaching in Chinese universities (Deng 2018).

It can be safely concluded that although the research in this field has been developing for more than ten years, there are still many unexplored areas especially in the application of process-oriented assessment in translation classroom. The research team, on the basis of previous research findings in Business Translation Course under flipped classroom context, built a comprehensive process-oriented assessment model and applied it to classroom evaluation with an aim to verify its effect, hopefully filling the gap in this research area in the academia.

\subsection{Status Quo of Assessment of Business English Translation Course in GDUFS}

Most of the flipped classroom practices in China still follow the traditional assessment method (Deng, 2018). Taking the Business Translation Course of the School of English for International Business of Guangdong University of Foreign Studies (GDUFS) as an example, although the process-oriented teaching model has been adopted in the past two years, traditional test-oriented summative assessment is still applied to assess the students' performance and competence. Usually, the teachers will grade students' 4-5 translation quizzes or assignments (accounting for 40\%) and final exams (accounting for 60\%). The final scores of students for this course is calculated after conversion of assignment scores and exam scores combined with weight. Table 1 is the summative assessment form currently applied in Business English Translation course for the third-year English majors at the School of English for International Business of Guangdong University of Foreign Studies (Deng 2018).

Table 1. Test-oriented summative assessment form

\begin{tabular}{llllll}
\hline & Assignment 1 & Assignment 2 & Assignment 3 & Assignment 4 & Final test \\
\hline Percentage & $10 \%$ & $10 \%$ & $10 \%$ & $10 \%$ & $60 \%$ \\
\hline
\end{tabular}


The following are the setbacks of the traditional summative assessment method reported by 10 teachers of this course in an interview done in May 2019.

1) As the only subject of translation assignment/examination text evaluation, the teachers' subjectivity is unavoidable in the assessment process. There is actually no standard answer or perfect translated version for any source text. The same source text may be rendered into several different translated versions with totally different styles due to different purposes of translation. However, a teacher's personal aesthetic and linguistic preference will consciously or unconsciously lead to subjectivity in grading the students' translated texts. In other words, the closer the students' choice of words and sentences to the teacher's personal preferences, the higher their scores might be. As Dr. Li (2006) pointed out, the most difficult problem in translation testing is the subjective and unreliable score of translation test papers. It is very difficult to achieve objectivity and consistency in the process of the students' translation assessment.

2) Taking several translation assignments/tests scores as the measurements of students' overall translation competence is actually detrimental to scientific assessment in translation course. Under the summative assessment model, students' learning psychology, motivation, choice of translation strategies and language processing and modification are often neglected. The purpose of translation teaching for English majors is to cultivate translation professionals with the ability to solve practical translation tasks. Yet, the scores of translation assignments and tests only partially reflect these abilities.

The negative guiding effect of the summative assessment in Business English Translation course cannot be ignored. The following are facts and ideas concluded in interviews done on 77 students and 4 teachers of this course.

1) Some students participate passively in class and lack interest in learning. They are tired of frequent translation quizzes and assignments and are in lack of exploration and innovation initiatives to solve practical translation tasks and problems.

2) Some students place too much emphasis on translation assignments/quizzes and final exam scores; The improvement of bilingual and encyclopedia competence is of less importance than getting higher scores in translation class.

3) Teachers are usually exhausted in scoring a large number of assignments, quizzes and exams. With limited time and energy, the teachers put themselves in the embarrassing cycles of delayed feedbacks to students' assignment, uneven allocation of time between teaching and evaluation, and lack of unity and continuity in teaching content and feedbacks.

\section{Preliminary Research Findings}

Since February 2016, the research team has carried out empirical studies on flipped classroom in Business English Translation course. This study, lasting two years and two semesters since 2016, investigated the validity of flipped classroom in two parallel classes of third year students of business English major. The participants were 65 students who were divided into one experimental group and one control group. The traditional teacher-oriented classroom teaching mode was used in the experimental group class, while the process-oriented flipped classroom teaching mode was implemented in the control group class (Deng 2018). Because of the informative and vocative nature of most business translation texts (Reiss, 1989), the research team designed a teaching process model of a combination of micro-course teaching, group project translation and peer evaluation for each chapter in the syllabus. The research team adopted the research methods of pre-test, questionnaires, interviews and after-test, and applied SPSS software to analyze the data collected in order to verify the efficacy of flipped classroom in business translation course. The following are the test data and results of this preliminary research (Deng, 127).

Table 2. Translation competence test results

\begin{tabular}{llllll}
\hline & $\mathrm{N}$ & Mean & Standard Deviation & $\mathrm{t}$ & $\mathrm{p}$ \\
\hline Experimental group & 32 & 84.4 & 8.716 & & \\
Control group & 33 & 79.8 & 12.364 & 3.456 & 0.011 \\
\hline
\end{tabular}

The above data show that the experimental class in translation ability tests scored an average of 84.4 , much higher than 79.8 of control group class. The standard deviation 8.716 of the experimental class is far lower than 12.364 of the control class. This proves clearly that individual translation competence of the students was improved and the differences between the students' translation competence were decreased after the 
implementation of flipped learning in business translation course. Flipped classroom is an effective teaching mode to improve students' learning initiative and translation competence.

At the end of this research, our team conducted a questionnaire among 65 students with five measurement domains, including (1) self-assessment of translation competence, (2) classroom participation, (3) motivation for learning after class, (4) mastery of language skills, and (5) evaluation of course assessment mode. 65 valid questionnaires were distributed and collected, and the following are the data analyzed and concluded by SPSS software (Deng, 2018).

Table 3. Questionnaires data

\begin{tabular}{lll}
\hline Measurement Domain & Mean $+/-$ SD & \\
\hline & The Experimental class $(\mathrm{n}=32)$ & The Control class $(\mathrm{n}=33)$ \\
\hline The Self - evaluation on competence & $4.40+/-0.29$ & $3.76+/-0.56$ \\
Participation in classroom & $4.65+/-0.36$ & $3.45+/-0.21$ \\
Motivation to learn out of class & $3.73+/-0.97$ & $3.33+/-0.46$ \\
The Mastery of Translation Skills & $3.86+/-0.79$ & $3.76+/-0.89$ \\
Satisfaction on assessment model & $2.95+/-0.20$ & $2.93+/-0.34$ \\
\hline
\end{tabular}

All the measurements ranged 1 to 5 .

SD: Standard deviation.

The above data show that the average scores of the experimental class in the first three measurement domain are significantly higher than those of the control class. This suggests that the implementation of flipped classroom in business translation class has significantly enhanced the students' self confidence in translation, greatly improves students' classroom participation (average from 3.45 to 4.65), and promoted the motivation of the students' autonomous learning after class. What's more, the higher average score of the students' translation competence test of the experimental class in Table 1 is also a sound support to the above-mentioned conclusion.

It should be pointed out that, in the fourth measurement domain of students' mastery of translation skills, the difference between the experiment and control group is not that distinctive $(3.86+/-0.79$ and $3.76+/-0.89)$. These data suggest that, in terms of the learning of translation skills, students' learning performance in the flipped classroom and traditional classroom are almost the same. This is also a clear demonstration of the fact that the teaching effect will not be affected when we extend the study of skills and knowledge from inside the classroom to the outside of the classroom. Flipped classroom extends the space and time span of traditional classroom. What's more, flipped classroom makes learners become the real learning subjects both in and outside the traditional classroom.

However, in terms of the assessment model, the control group and the experimental group presented almost identical data $(2.95 \pm 0.20$ and $2.93 \pm 0.34)$, which indicates that the current assessment model is not compatible with the modern teaching model of flipped classroom. Therefore, it is of great significance to construct a process-oriented assessment model that is suitable for the new teaching model (Deng, 2018).

\section{The Process-oriented Assessment Models in Business English Translation Course in a Flipped Classroom Context}

Teaching, learning and assessment are three mutually integrated and mutually promoting factors in a complete classroom teaching process. The process-oriented and student-oriented flipped classroom model inevitably requires the assessment mechanism to lay emphasis on the learning process and take learners' complete learning activities before and after class as the evaluation object. Under the traditional summative evaluation model, the evaluation standard is preset by teachers and the evaluation standards are one-way directed. A scientific and complete assessment model in the flipped classroom of business translation course should incorporate different assessment subjects and multiple assessment criteria.

Based on our preliminary research findings, the research team incorporated multiple assessment methods including micro learning log, project translation project, self-evaluation, group evaluation, peer review, translation $\log$ and recording of students' oral evaluation and etc. into the flipped classroom of business translation course. The research team designed a process-oriented assessment models as shown in Figure 1 and 2. Figure 1 shows the complete process of learning activities of the students before, in and after class in a flipped classroom context. Figure 2 demonstrates the multiple subjects of the assessment process of translation course in a complete flipped learning context. 
The team applied this process-oriented assessment mechanism to the five main chapters of Business English Translation course: advertising translation, tourism text translation, business letter translation, enterprise publicity text translation and contract translation. The overall learning time in class was designed to be 15-18 hours, i.e. 10-12 translation classes (10-12 weeks), which covered almost $2 / 3$ of the whole semester.

Taking the chapter of tourism translation as an example, due to the limitation of class time, it usually takes 2-3 translation classes to complete a themed chapter, that is, three hours of class time and several times before and after class ( 80 minutes for each class). It should be noted that, since the course is generally divided into two periods, the complete assessment model should cover five periods: before class - the first class - after the first class - the second class - after the second class in terms of time flow in the actual operation of teaching and learning.

As have already designed in our preliminary research, the research team randomly divided the students into one client group and 4-5 translation groups for a classroom translation project in each teaching chapter. The client group, as the initiator of the translation project, was responsible for the selection of the translated text. They should select a proper text on a related topic before the class begins, and then submit it to the teacher for approval. The teacher only played the role of guidance and suggestion in this process.

\subsection{Process-Oriented Assessment Model from the Perspective of Complete Learning Process}

In order to ensure the integrity of learning activities in the process-oriented assessment, our research team has set up a process-oriented assessment model covering the complete learning activities before, during and after class in the flipped classroom of Business English Translation course from the perspective of learners' learning process, learning psychology and motivation (Figure 1). This process-oriented assessment model serves as a guiding framework in organizing the learning activities of the students inside and outside the classroom from a diachronic perspective.

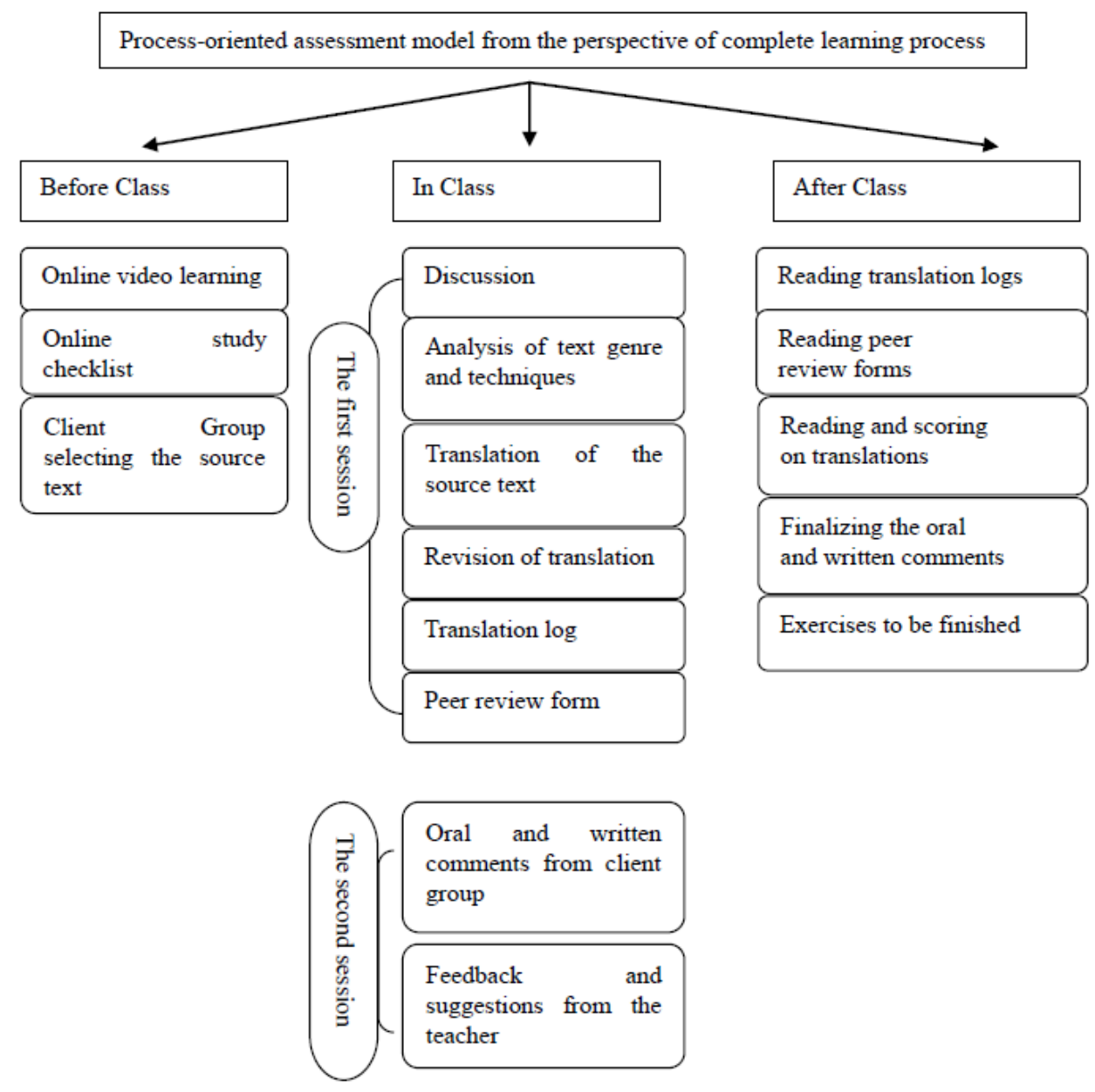

Figure 1. Process-oriented assessment model from the perspective of complete learning process 


\subsubsection{Before Class}

As the subjects of pre-class learning activities, the students are divided into one client group and 4-5 translation groups. The pre-class learning activities of the client group includes selecting the translation source text and communicating with the teacher; the translation groups should watch the on-line instruction video and finish the checklist exercises. Considering the features of business English translation course, the research team have decreased the traditional classroom teaching of translation skills to 15-20 minutes and recorded the content in advance in the form of online videos.

Take tourism text teaching as an example: the on-line video includes introducing the tourism text from the perspective of functional and vocative text, introducing the treatment of tourism jargons both in English and Chinese, and finally illustrating skills and strategies in the translation of tourism text with a few selected parallel texts. The checklist exercise of the teaching videos includes the review and practice of the teaching content, the test of the mastery of major translation skills and text styles, and the students' reflection on their own learning effect. Before the class begins, the teacher reviews the students' checklist exercises so as to obtain a preview of the students' overall mastery of the required skills and knowledge learning.

\subsubsection{During The First Session of Class}

Firstly, with proper evaluation of the learning effects of the students obtained through online learning checklist exercises, the teacher communicates with students in class, raises questions in the form of case analysis and discussion, and leads students to review some crucial knowledge and skills in business translation.

Secondly, the client group presents the tourism text to all the translation teams in the form of a business project. This classroom translation project will take about one hour. Each team member of the translation groups will undertake different tasks in annotating and translating the project text including text style analysis, translation supporting materials search, translation commentary writing, translation verification and modification. Project translation is designed on purpose as a classroom task so that teachers can observe, guide and evaluate students' translation activities and process when the translation teams are working on the task. Students of the translation groups become the real subject of translation activities and center of learning. The teacher's assessment can also be carried out in a three-dimensional way and from the perspective of an observer of the classroom.

Finally, due to the different level of cooperation of each group and different translation competence of individual students, the translation progress of each group may differ greatly. Therefore, it is expected that some translation groups will submit their translation in class while other groups will submit after class. The translation submitted by each group should be accompanied by a translation $\log$ and peer review form. The translation $\log$ shall include a report on the translation strategies adopted by the translation team, the use of translation supporting materials, and the modification process of the translation. Peer review is the evaluation of other team members' performance in the process of translation.

\subsubsection{After the First Session of Class}

After receiving the translations peer review forms and translation logs submitted by all translation teams, the client team will first read all the materials and finally evaluate the translations. During the evaluation process, the client group will discuss with the teacher online or over the phone. The teacher provides the client team with the translation assessment criteria used in the MA program in Applied Translation Studies at the University of Leeds (Mu, 2006). The Assessment criteria are divided into four subscales as follows (Xu \& Deng, 2020):

1) Accuracy of vocabulary

2) Accuracy of grammar

3) Appropriateness of stylistic features

4) Completeness of information transmission

Based on the assessment criteria, the client group should present the reason why they would prefer this version to the others in written form and write comments and suggestions on each translator group's work (Deng, 2018). At last, the client team will choose the best translation.

\subsubsection{During The Second Session of Class}

The client team provides oral and written evaluation in the second session of class. The teacher records the performance of all the students in this process of group peer review. Then, on the basis of the evaluation of the client group, the teacher evaluates and elaborates the translation quality of each group, summaries the evaluation of the client group and the classroom performance of all students as a whole. Lastly, the teacher, as the 
director-in-general, made final comments on each group's performance and summarized the key notes of this chapter (Deng, 2018).

\subsubsection{After the Second Session of Class}

The teacher collects translations, translation logs, peer review forms, and recordings of written and oral evaluations of translation groups by client group. Then the teacher reviews and evaluates students' mastery of all the required skills and knowledge.

\subsection{Process-oriented Assessment Model from the Perspective of Multiple Assessment Subjects}

From the perspective of multiple assessment subjects, the research team constructed a second model of multiple evaluation subjects in business translation course in a flipped classroom context (Figure 2). In modern assessment culture, the subject of assessment should not be a single person like the teacher or the instructors (Gao, 2004). In this model, specific evaluation contents implemented by different assessment subjects (teacher assessment, student self-assessment, peer review) are categorized respectively so as to draw a clear picture of this process-oriented assessment paradigm from a synchronic perspective.

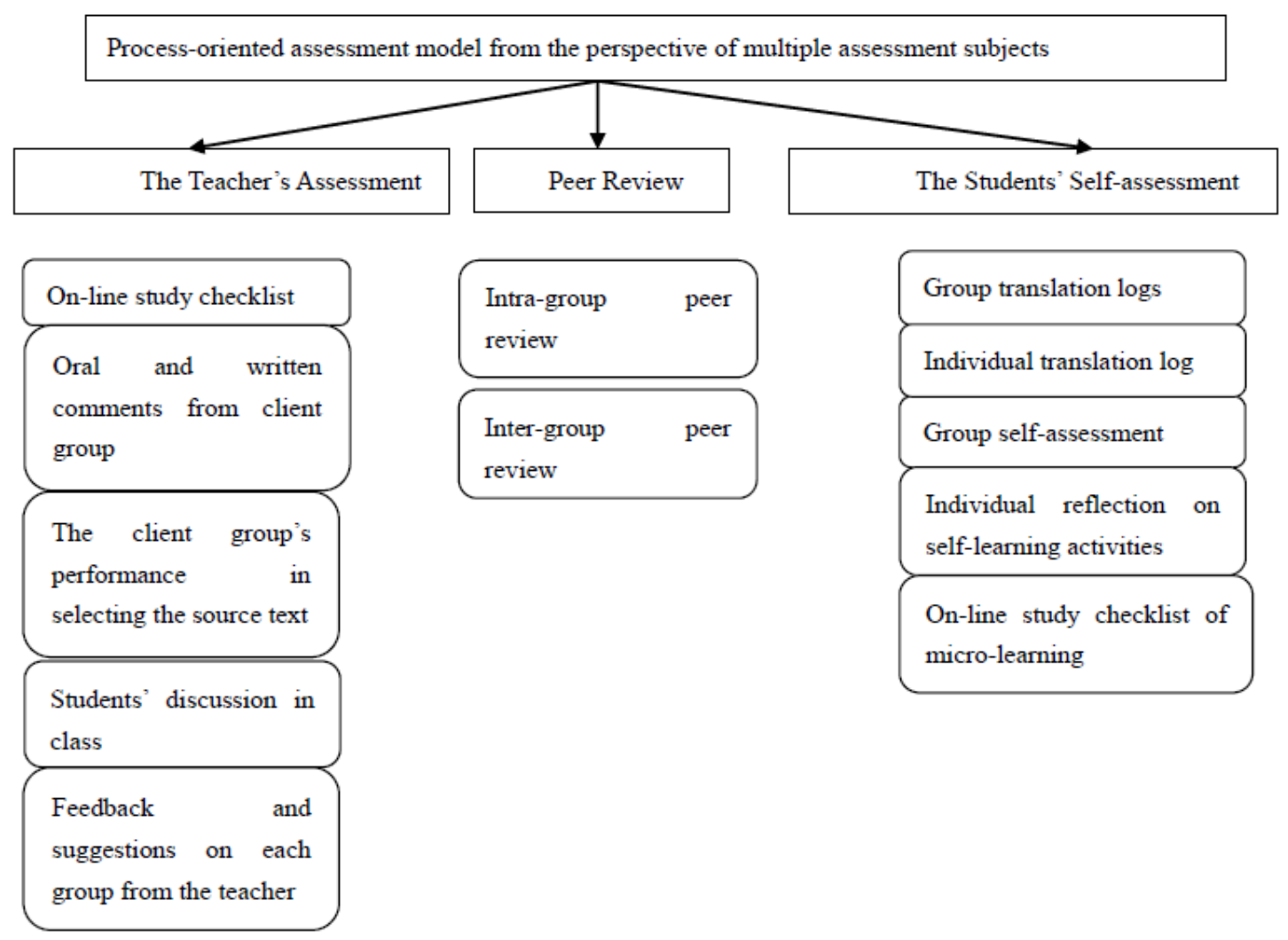

Figure 2. Process-oriented assessment model from the perspective of multiple assessment subjects

\subsubsection{The Students' Self-assessment}

Students' self-assessment involves the students' reflection on self-learning activities (individual and group). In the individual self-assessment of students, an online study checklist and a self-evaluation task are designed; in the group self-assessment, two evaluation tasks are designed: group self-evaluation and group translation log. The design of online study checklist is to test of the students' mastery of key knowledge and skills in a flipped context. The content of the translation log includes the presentation of the division of labor among team members, the use of translation tools and materials, the analysis of text style, the adoption of translation strategies in the process of translation, the difficulties encountered in translation and the subsequent verification and modification of the translation. The design of the elf-evaluation tasks identifies with the process-oriented nature of translation. The purpose of these designs is to lead the students constantly examine and reflect upon the process of translation and learning, so as to improve the efficiency of learning and the quality of translated texts. 


\subsubsection{Peer Review}

The research team designed two kinds of peer review, namely intra-group and inter-group peer review, both of which are to be completed after class. Under the paradigm of project-based flipped classroom in business translation course, the whole class in one curriculum chapter is randomly divided into one client group and several translation groups in competitive relationship, and the latter parties' translated text will be evaluated by the client group so that the best translation will be selected. Intra-group peer review is bidirectional and multi-dimensional. The assessment measurements are usually the level of completion of translation task, the understanding of the style of the source text and the mastery of the style and content of the target text. Inter-group assessment is unidirectional and one-dimensional. The client team is the only subject in assessing the translation team's translated texts. The assessment results are completed by written report and rating.

\subsubsection{The Teacher's Assessment}

Under the category of teacher's assessment, this model represents the teacher's participation in the teaching and learning as an observer and guider before, during and after class. Reviewing of the on-line study checklist and evaluating the source text selected by the client group are teachers' pre-class assessment activities. During the class, the students is the only subject of learning activities, therefore the teacher is able to observe students' translation process in simulated real translation projects. After class, by reviewing students' self-evaluation, translation logs and translated texts, the teacher can obtain a timely and in-depth understanding of the students translation process and competence, and on this basis, adjusts the teaching and learning design in the next chapter. Finally, the teacher summarizes all the assessment results in this chapter to determine each student's mastery of key knowledge points and the degree of completion of translation tasks.

It should be reiterated that Model 1 and Model 2 are two different perspectives in presenting and implementing of the process-oriented assessment in business translation classroom. From the perspective of time axis, Model 1 is synchronic and Model 2 is diachronic. From the perspective of content, the two models are two different angles of the same learning and teaching activity.

\section{Research Method and Procedure}

\subsection{Participants}

In order to evaluate the efficacy of the process-oriented model in Business English translation course in the flipped classroom context, besides the already existing experimental and control group in the preliminary research since 2016, the research team added two experimental classes (60 students in total) and two experimental classes (59 students in total). The participants in this empirical study are therefore in total 181 third-year students of English major, 92 in experimental class and 89 in control class. A pre-study translation test was conducted before the implementation of the assessment model at the beginning of the new semester. The results of this pre-test indicate that the two groups' scores were not significantly different as shown in Table 4 .

\subsection{Procedure}

After a complete semester of Business Translation Course in a flipped classroom in the process-oriented assessment model, the research team tested the experimental and control groups in a comprehensive business translation test. The purpose of the pre-test and post-test is not to evaluate students' performance in translation courses and their translation competence, but to examine the degree of students' acquisition of translation knowledge and skills, and at the same time, evaluate the change of student's translation competence after the implementation of the process-oriented assessment model. The data and findings of a comparative analysis of these two tests are presented in Table 4.

It has to be clarified that in the preliminary research our research team has collected questionnaires from both the experimental class and the control class with five measurement domain including self-evaluation on competence, participation in classroom, motivation to learn out of class, the mastery of translation skills, satisfaction on assessment model (Deng, 2018). As a result, in this second stage of research on the process-oriented assessment model, the research team focuses mainly on the validity and efficacy of the assessment model and designed questionnaires only for the 92 students in the experimental class.

According to the English Competence rating scale issued in 2018 by State Language Committee of Ministry of Education of China, the research team designed 30 questions in the questionnaire in the following measurement domains: (1) the objectivity and efficacy of peer review, (2) self-assessment of individual students in the translation process, (3) the completeness of the teacher's assessment, (4) the leading and instructional role of the teacher, (5) self-assessment on the growth of individual translation competence. 


\section{Results}

\subsection{Data from the Pre-test and Post-test}

Table 4 presents the pre-test and post-test result of the experimental class and the control class. It is worth mentioning that the number of testees in the experimental class is 92 and 89 in the control class. The results of the pre-test show that there is no great difference between the experiment group and the control group with the average scores being 86.12 and 85.96 respectively. After the implementation of project-based flipped learning model and process-oriented assessment model, the experimental class has obtained higher average score of 89.57 (100 total) than that of themselves (86.12) in the pre-test and also that of the control group (84.90) in the after-test. It can be safely concluded that the process-oriented assessment model combined with the project-based flipped learning model in the preliminary research has virtually enhanced the students' translation competence.

The standard deviation of 8.102 of the experimental class in the after-test also clearly demonstrates that the difference between individual learners in the experimental class is reduced, comparing to 10.981 of the control class. It is a proof that this new learning and assessment model is more effective in engaging more students in productive learning in and out of class with the carefully-designed project translation tasks and process-oriented assessment (Deng, 2018).

The $\mathrm{T}$ value of 1.135 and the $\mathrm{P}$ value collaboratively indicate that the difference in translation competence between the experimental class and control class is greater after the implementation of the new teaching and assessment model (Deng, 2018).

Table 4. Pre-test and post-test result

\begin{tabular}{llllllll}
\cline { 2 - 8 } Tests & \multicolumn{2}{c}{ Experiment group } & \multicolumn{2}{c}{ Control group } & \multicolumn{2}{c}{ t-test scores } \\
\cline { 2 - 8 } & $\mathrm{M}$ & $\mathrm{SD}$ & $\mathrm{M}$ & $\mathrm{SD}$ & $\mathrm{t}$ & $\mathrm{p}$ \\
\cline { 2 - 8 } & Pre-test & 86.12 & 6.26 & 85.96 & 10.981 & 0.364 & $* *<.001$ \\
After-test & 89.57 & 7.81 & 84.90 & 8.102 & 1.135 & $* .019$ \\
\hline
\end{tabular}

Notes: $* \mathrm{p}<.05, * * \mathrm{p}<.01$

\subsection{Data from Questionnaires}

As have mentioned above, in the second stage of this research, the research team focuses mainly on the validity and efficacy of the assessment model and designed questionnaires only for the 92 students in the experimental class. Consequently, the data collected are only from the experimental class.

The five measurement domains focus on the efficacy of the process-oriented assessment model applied in business English translation course in a flipped classroom context. The mean score of 4.66 and standard deviation of 0.29 of the first domain demonstrate that most students in the experiment class are satisfied with the objectivity of group assessment and peer review. The mean score of 4.40 and standard deviation 0.36 of the second domain show that most students in the experiment class identify with the objectivity of group assessment. The data demonstrate a significantly high response to the third and fourth domain of completeness of the teacher's assessment and instructional role of the teacher in the teaching and learning process. It is a sound support to the efficacy of the process-oriented assessment model under which the teachers are seen by the students as more involved in the learning process even though the teachers have actually quitted from the center of the classroom and took on the role of observers of the classroom. The lowest mean score in the five measurement domains is the students' self-assessment on their own translation competence growth. It shows that in the future design of the flipped classroom under process-oriented assessment model, the research team should spare no efforts in enhancing the student's self-confidence in their translation competence.

Table 5. Data collected from questionnaires

\begin{tabular}{lll}
\hline Measurement Domain & Mean & SD \\
\hline The objectivity of peer review & 4.66 & 0.29 \\
The objectivity of group assessment & 4.40 & 0.36 \\
The completeness of the teacher's assessment & 4.89 & 0.97 \\
The instructional role of the teacher & 4.76 & 0.79 \\
Self-assessment on translation competence growth & 4.05 & 0.20 \\
\hline
\end{tabular}

All the measurements ranged 1 to 5 . 


\section{Discussion}

This paper is an empirical study on the efficacy of process-oriented assessment model in a flipped classroom in Business English Translation course. The study, lasting four years, is divided into two experimental stages. The preliminary stage mainly focuses on the implementation and testing of project-based flipped learning in Business English Translation course. The second stage focuses on the implementation and efficacy of the process-oriented assessment model design by the research team. It is an urgent call to adopt a new assessment model compatible to the flipped learning context in Business English Translation course because teaching, leaning and assessment should be in a positive and productive circle. What's more, it is also of crucial significance that the assessment model should be in line with the nature of translation process. The research findings of this paper are as follows:

The process-oriented assessment model has been statistically proved to be effective in Business English Translation course not only because it has significantly strengthened the students' learning efficiency and translation competence, but also because it responses to the nature of translation by emphasizing the process of translation activities of students, rather than merely on the translation product (Deng, 2018). The student turned from passive listeners and followers in the assessment model into the subject and center of assessment. By incorporating multiple assessment subjects including the teachers and the students themselves and observing the assessment process from the diachronic perspective of before, during and after class, this process-oriented assessment model has statistically proved to be high effective in enhancing the student's translation competence and also their involvement in leaning in and out of class.

\section{Limitations}

The limitations of this study are the following aspects. Firstly, the research has a limited number of participants in this four-year study. The preliminary stage of this empirical study included only 65 students in total. The statistics and findings could be more convincing if we had included more participants from the beginning of the study. Secondly, the new assessment model is very time-consuming because of multiple subjects in assessment and complicated processing procedure. The research team paid great efforts and much time in collecting and analyzing numerous data, reviews, forms logs and reports, which was actually beyond the time and energy of a single teacher for one course. The research team should work out a more effective mechanism in implementing this new model in Business English Translation course under a flipped classroom context.

\section{Acknowledgements}

This paper is funded by the 2017 Higher Education Teaching Research and Reform Project of Guangdong Province "Study on the Process-oriented Assessment Model of Business English Translation Course in a Flipped Learning Context" (No.: 103-XCQ18027).

\section{References}

Abeysekera, L., \& Dawson, P. (2015). Motivation and cognitive load in the flipped classroom: Definition, rationaleand a call for research. Higher Education Research \& Development, 34(1), 1-14. https://doi.org/10.1080/07294360.2014.934336

Chang, C. (2002). Building a web-based learning portfolio for authentic assessment. International Conference on Computers in Education, 27(4), 129-133. https://doi.org/10.1109/CIE.2002.1185883

Chen, J. (2013). Process assessment in translation teaching. Journal of Southwest University of Science and Technology (Philosophy and Social Science), 30(2), 51-57.

Deng, L. (2018). The project-based flipped learning model in business English translation course: learning, teaching and assessment. English Language Teaching, 11(9), 118-128. http://doi.org/10.5539/elt.v11n9p118

Gile, D. (1994). The Process-oriented approach in translation training. In C. Dollerup \& A. Lindeaard. (Eds.), Teaching Translation and Interpreting: Insights, Aims, Visions (pp.96-97). Amsterdam, John Benjamins. https://doi.org/10.1075/btl.5.17gil

Gao, L. (2004). Reflections on process assessment. Curriculum, Textbook and Teaching Method, 24(10), 15-19.

Ji, Y., \& Zhang, J. (2013). Teachers' confusion and solutions in the implementation of process assessment. Contemporary Education Science, 46(13), 23-25.

Liu X (2014). Application of formative assessment in process translation teaching. Journal of Hubei. Correspondence University, 27(16), 122-123.

Li, X. (2015). Research on teaching quality evaluation system of flipped classroom. Audio-visual Education Research, 42(3), 96-100. 
Li, D. (2006). Student-centered translation curriculum. Foreign Languages, 21(2), 59-65.

Mu, L. (2006). Translation testing and grading. Foreign Language Teaching and Research, 38(6), 466-471.

Nord, C. (1997). Translating as a Purposeful Activity: Functionalist Approaches Explained. Manchester, UK, St Jerome Publishing.

Olohan, M. (2010). Commercial translation. In Y. Gambier \& L. van Doorslaer (Eds.), Handbook of Translation Studies (Volume 1) (pp. 41-44). Amsterdam/Philadelphia: John Benjamins Publishing Company.

Rout, P. (2011). A new framework for standardization and certification for process assessment. Software Quality Professional, 14(1), 4-15.

Reiss, K. (1989). Text types, translation types and translation assessment. In A. Chesterman (Ed.), Readings in Translation Theory (pp. 105-115). Helsinki, Oy Finn Lectura Ab.

Wen, T. (2016). Research on the process evaluation of effective flipped classroom: a case study of English Chinese translation course. Chinese Language Journal, 36(5), 134-136.

Wu, W. (2006). Concept and method of process evaluation. Curriculum, Textbook and Teaching Method, 26(6), 15-19.

Xie, T., \& Li, Y. (2009). Process evaluation: on the construction process of learning process value. Theoretical Discussion, 32(6), 17-20.

Zheng, M. (2010) Research on organizational strategies and methods of process evaluation. China Audio-Visual Education, 57(9), 107-109.

Zhong, M. (2005). Process assessment: concept, scope and implementation. Contemporary Education Science, $21(14), 44-47$.

Zhang, S. (2012). Philosophical interpretation of process assessment. Qilu Journal, 38(4), 69-73.

\section{Copyrights}

Copyright for this article is retained by the author(s), with first publication rights granted to the journal.

This is an open-access article distributed under the terms and conditions of the Creative Commons Attribution license (http://creativecommons.org/licenses/by/4.0/). 